\title{
Optimization and in-vitro Evaluation of Poly (lactic acid) /Mesalazine Microspheres as Drug Carriers
}

\author{
Wafa Banabid ${ }^{1}$, Ferhat Djerboua ${ }^{1}$, Amor Maiza², Zineb El Bahri ${ }^{3^{\star}}$, Milad Baitiche ${ }^{1}$ \\ 'Laboratory of Multiphase Polymeric Materials (LMPMP), Faculty of Technology, University Sétif-1, DZ-19000, Sétif, ALGERIA. \\ ${ }^{2}$ SALEM Laboratory, El-Eulma, ALGERIA. \\ ${ }^{3}$ Laboratory of materials \& Catalysis, Faculty of Exact Sciences, Djillali Liabes University of Sidi Bel Abbes, 22000 ALGERIA.
}

\begin{abstract}
Purpose: The present study is intended to the preparation and optimization of controlled drug release microparticles based on polylactic acid and Mesalazine. This active ingredient is usually used in the therapy of intestine inflammatory diseases, particularly the Crohn's disease and hemorrhagic recto colitis. Methods: Microencapsulation by simple O/W emulsion solvent evaporation method was used to prepare these formulations. Some of the process variables such as the emulsifier concentration, the polymer concentration, the drug: polymer ratio and stirring speed were varied and the obtained biodegradable microparticles were characterized by FTIR spectroscopy, X-ray diffraction, DSC method and optical microscopy. The drug release was established both in simulated intestinal fluid and distilled water and the data analysis and the release mechanism were investigated on the basis of Higuchi and Korsmeyer-Peppas models. Results: The microparticles' size i.e. the number mean diameter (d10) ranged from 127 to $744 \mu \mathrm{m}$ and the drug content varied from 12 to $27 \%$. The effect of the selected variables on the microparticles' characteristics (size, morphology and drug release) were exhaustively discussed for the $\mathrm{PLA} /$ mesalazine microparticles' optimization. Conclusion: This study showed that the microparticles' morphology depended strongly on the emulsifier concentration and the drug entrapment is related to the initial drug:polymer ratio and polymer concentration.
\end{abstract}

Key words: Microencapsulation, Polylactic acid, Mesalazine, Microparticles, Process variables, Optimization

\section{INTRODUCTION}

Mesalazine also known as mesalamine (5-aminosalicylic acid) is the amino derivative of salicylic acid, this molecule possesses an amphoteric character due to the presence of the carboxyl and amino groups. So; the value of the $\mathrm{pH}$ medium has a strong effect on its solubility and protonation. As well as, the solubility and ionization properties of mesalazine affect its intrinsic release rate and matrix carrier characteristics; then, its formulation for release in the colon is problematic and requires a special coating to prevent gastric release. ${ }^{1,2}$

Mesalazine is preconized for the treatment of mild to moderate active ulcerative colitis; it is a potent inhibitor of cyclooxygenase, which leads to the decrease of the produc- tion of prostaglandin E2 produced during intestinal inflammation. It also produces the blocking of the path of lipoxygenase which will lead to inhibition of the production of hydro-peroxy-eicosate trienoïc acid and leukotriene B4. Its effectiveness as an antiinflammatory agent is probably due to its effect on the metabolism of leukotrienes. ${ }^{3,4}$ Different drug formulations have been developed in order to enhance the drug effectiveness and to attain the drug controlling and targeting, these formulations especially employ a $\mathrm{pH}$-dependent release mechanism. ${ }^{5,6}$

Polymeric microspheres received more attention in recent years and have emerged
Submission Date: 20-12-2016; Revision Date: 24-01-2017; Accepted Date: 15-02-2017

DOI: 10.5530/ijper.51.2s.49 Correspondence: Zineb* El Bahri, Laboratory of materials \& Catalysis, Faculty of Exact Sciences, Djillali Liabes University of Sidi Bel Abbes 22000, ALGERIA

Phone: 213-48-747680

E-mail: elbahrizineb@ yahoo.fr

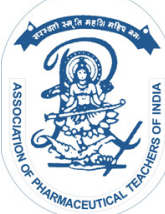

www.ijper.org 
as the most promising carriers able to improve the site specific release characteristic of drugs. ${ }^{7-11}$ For example, ethylcellulose, eudragit S-100 and chitosan were used to produce magnetic microspheres loaded by mesalazine and the results demonstrated that chitosan microspheres offered the best results in term of drug release. ${ }^{8}$ Cross-linked chitosan microparticles using mont-morillonite were also prepared and tested to enhance the mesalazine efficacy. ${ }^{10}$ In other researches, $\mathrm{PCl}$ (polycaprolactone) was also used for producing new mesalazine nanoparticles. ${ }^{12}$

Also, it is well known that in the drug formulation field, the most widely used and studied class of biodegradable polymers is the poly-esters including PLA poly(lactic acid), poly(glycolic acid), and their copolymers. ${ }^{13}$ Using this type of polymers, only, Mahajan et al. ${ }^{14,15}$ have prepared and tested mesalamine/ PLGA loaded nanoparticles and demonstrated that these formulations showed selective adherence and enhanced drug accumulation into colitis tissues.

So, in the present study, PLA was selected as drug carrier for the preparation and optimization of mesalazine microspheres; this type of formulations was not conveyed and highlighted in the literature. For the purpose, PLA microparticles loaded by mesalamine were produced by microencapsulation process using simple emulsion-solvent evaporation technique.

In fact, the formulation and the process variables have a strong effect on the microparticles' characteristics and especially on the drug release. Then, in this work, to optimize the experimental conditions, the emulsifier, polymer and drug concentrations and the stirring speed have been varied and studied; the effects of the selected variables on the microparticles' shape, the drug entrapment and the drug release were investigated and discussed.

\section{MATERIALS AND METHODS}

\section{Materials}

Poly (lactic acid) (PLA, NatureWorks $\mathrm{Tg}=65^{\circ} \mathrm{C}, \mathrm{Tm}=$ $158^{\circ} \mathrm{C}$ ), mesalazine SALEM laboratory (Algeria). Polyvinyl alcohol (PVA) (Mw=13,000 to 23,000 g/mol (98\% hydrolyzed) provided from Sigma-Aldrich was used as emulsifier agent and Dichloromethane DCM (from Merck specialties) used as organic solvent.

\section{Methods}

\section{Microparticles' preparation}

The microparticles lots (Table 1) were prepared by the conventional method of microencapsulation by emul- sion - solvent evaporation. The aqueous phase was prepared by dissolving $(0.1 \% ; 0.5 \% ; 1.5 \%)$ of PVA in 500 $\mathrm{ml}$ of distilled water with vigorous stirring and heating if necessary to $90^{\circ} \mathrm{C}$. Mechanical stirrer type Heidolph RZR 2041 was used for the emulsion preparation. The organic phase composed from PLA $(0.5 \mathrm{~g}, 1 \mathrm{~g}, 2 \mathrm{~g})$ and mesalazine as active principle (AP) (1 g) dissolved in 20 $\mathrm{mL}$ of DCM was emulsified gradually in the external phase previously prepared and cooled at room temperature. The Stirring was maintained for 3 hours for a complete evaporation of the solvent i.e. solidification of the microparticles. Then, the solution was filtered and washed 2 to 3 times with distilled water. The recovered powder was dried in a desiccator.

\section{Determination of drug content}

Drug content was determined as following in triplicate: $20 \mathrm{mg}$ of microparticles were soaked in adequate quantity of $0.01 \mathrm{~N}$ of hydrochloride aqueous solution (30 $\mathrm{ml})$. The suspension was shacked vigorously for $5 \mathrm{~h}$, then was filtered and diluted suitably. The resulting solution was analyzed by UV-Vis spectroscopy at $302 \mathrm{~nm}$ of wave length where $\square=0.025 \mathrm{~L} \cdot \mathrm{mg}^{-1} \cdot \mathrm{cm}^{-1}$. The active ingredient content and the microencapsulation efficacy are calculated from equation 1 and 2 respectively.

\section{Characterization of microparticles}

Microparticles were characterized using various methods. The FT-IR spectra were recorded using a FTIR spectrophotometer (JASCO). The X-ray diffraction analysis were carried out with a diffractometer PANalytical kind X'PERT PRO-operating at $40 \mathrm{kV}$ and $30 \mathrm{~mA}$ with $\mathrm{Cu}$ radiation $0.154 \mathrm{~nm}$ (nickel filter). The samples were scanned in the range 0 to $60^{\circ}$ of $2 \square$. For differential scanning calorimetry DSC samples were studied under a nitrogen atmosphere from $25^{\circ} \mathrm{C}$ to $350^{\circ} \mathrm{C}$ with

$$
\begin{aligned}
& \text { Drug content } \%=\frac{\text { mass of active agent extracted } * 100}{\text { mass of microparticles }} \\
& \text { Efficacy } \%=\frac{\text { actual drug content } * 100}{\text { theoretical drug content }}
\end{aligned}
$$

a heating rate of $10^{\circ} \mathrm{C} \cdot \mathrm{min}^{-1}$. Also, the microparticles' shape was examined under an optical microscope, the microparticles powder was dispersed in water and deposited on a glass slide and observed at different magnifications.

The mean diameters and size distribution $(\delta)$ of microparticles were calculated from the following equations and by measuring and counting more than 500 microparticles using appropriate lenses. 


$$
\begin{aligned}
& \mathrm{d}_{10}=\sum n i d i / \sum n i \\
& \mathrm{~d}_{32}=\sum n i d_{i}^{3} / \sum n i d_{i}^{2} \\
& \mathrm{~d}_{43}=\sum n i d_{i}^{4} / \sum n i d_{i}^{3} \\
& \delta=\mathrm{d}_{43} / \mathrm{d}_{10}
\end{aligned}
$$

\section{In vitro drug release studies}

The drug dissolution was performed in two media i.e distilled water and simulated intestinal medium $\mathrm{pH}$ (buffer solution of $\mathrm{pH}=6.8)$. In a closed dissolution reactor $(1 \mathrm{~L})$, kept at a temperature of $37^{\circ} \mathrm{C} \pm 0.5^{\circ} \mathrm{C}$ with a controlled rate stirring (400 rpm) using paddle apparatus (HeidoLph RZR 2041), $200 \mathrm{mg}$ of microspheres are soaked into $900 \mathrm{ml}$ of the dissolution medium At the desired time, $3 \mathrm{~mL}$ of the solution were withdrawn using a syringe filter, analyzed by UV spectroscopy (UNICAM UV model 300) without dilution at $298 \mathrm{~nm}$ $\left(\square=0.023 \mathrm{~L} \cdot \mathrm{mg}^{-1} \cdot \mathrm{cm}-1\right)$ in water medium and at $332 \mathrm{~nm}$ $\left(\square=0.017 \mathrm{~L} \cdot \mathrm{mg}^{-1} \cdot \mathrm{cm}^{-1}\right)$ in the buffered solution.

\section{Drug release data analysis}

The release profile and dissolution rate constitute important characteristics in the control of the drug formulation. Using mathematical equations, the release mechanism and behavior can be described and elucidated as functions of some parameters related to the pharmaceutical dosage forms. Some of the most relevant and commonly used mathematical models describing the drug dissolution curves from pharmaceutical systems are: zero order, first order, Higuchi, BakerLonsdale, Hixon-Crowell and Korsmeyer-Peppas. These models are resulting from a simple phenomenon (diffusion), or a determination of the rate-limiting step of kinetics. ${ }^{16}$

In this work, the Higuchi, Korsmeyer-Peppas and HixonCrowell models were applied to describe the dissolution profiles of mesalazine from the obtained microspheres. Higuchi $(1961,1963)$ developed several theoretical models to study release of high and low water soluble drugs incorporated in semi-solid and/or solid matrices; drug release was described as a square root time dependent diffusion process based on Fick's law. ${ }^{17,18}$ This relation can be used to describe drug dissolution from several types of modified release pharmaceutical dosage forms, as of some transdermal systems ${ }^{19}$ and from matrix tablets of water soluble drugs. ${ }^{20,21}$ Korsmeyer and Peppas (1984) developed an empirical equation to analyze both Fickian and non-Fickian release of drug from swelling as well as non-swelling polymeric delivery systems. ${ }^{22}$ The Hixson-Crowell cube root law (1931) describes the release from systems where there is a change in surface area and diameter of particles or tablets. ${ }^{23}$

The choice of best model which describe the release mechanism is based on the value of $r^{2}$ (correlation coefficient) obtained after plotting the experimental results according to the corresponding equations models studied (equations 7,8 and 9).

Higuchi model:

$$
\frac{M_{t}}{M_{\mathrm{i}}}=K_{\mathrm{H}} t^{1 / 2}+a
$$

Korsmeyer-Peppas equation:

$$
\frac{M_{t}}{M_{\mathrm{i}}}=K_{\mathrm{K}} t^{n}
$$

Hixon-Crowell equation

$$
Q_{0}^{1 / 3}-Q_{t}^{1 / 3}=K_{\mathrm{s}} t
$$

Where $Q_{t}(g / L)$ is the amount of drug dissolved in time $\mathrm{t}$ (min); $\mathrm{Q}_{0}$ is the initial amount of drug in the solution (most times $\mathrm{Q}_{0}=0$ ); $\mathrm{M}_{\mathrm{t}} / \mathrm{M}_{\mathrm{i}}$ is the fractional drug release; $K_{H}, K_{K}$ and $K_{s}$ are, respectively the Higuchi's, the Korsmeyer's and Hixon-Crowell's release constants; and $\mathrm{n}$ is an exponent which characterizes the drug release mechanism.

\section{RESULTS AND DISCUSSION}

\section{Microparticles' characterization}

The mesalazine/PLA microparticles entrapment efficiency varied from 12 to $27 \%$ (Table 2 ). We remarked that the drug entrapment can be increased practically when we used 2:1 of AP:PLA. The photomicrographs recorded by the optical microscope showed particles with different aspects, samples of (A) and (B) are in the form of aggregates with a low number of individual microspheres (Figure $1 \mathrm{~A}$ and B). Otherwise (D) has a significant amount of pseudo-spherical vesicles ranging from 100 to $200 \mu \mathrm{m}$ with a mean number diameter $\mathrm{d}_{10}$ of $127 \mu \mathrm{m}$ (Figure 1D).

For (C) and (E); spherical individual particles but with a larger diameter $\left(\mathrm{d}_{10}\right.$ equal to 708 and $744 \mu \mathrm{m}$ respectively) are observed (Figure $1 \mathrm{C}$ and $\mathrm{E}$ ). By comparing C, D and $\mathrm{E}$ microparticles batches, the mean diameter of $\mathrm{D}$ microspheres is a lower, this can be explained by the low percentage of polymer (PLA) in the organic phase which induced a low viscosity and so small size of droplets. $^{24}$ If we compare $\mathrm{C}$ and $\mathrm{E}$ batches, the mean diameter increased slightly when the percentage of PLA increased from 5 to $10 \%$, the effect of this parameter is not notable because in the same time the $\%$ PVA was 
increased, and it is known that a high concentration of emulsifier agent must decrease in general the droplet's size. $^{24}$

The FTIR analysis confirmed the actual existence of mesalazine in microparticles. In fact, the FTIR spectrum of pure mesalazine (Figure 2-1) shows absorption bands between $3600-3200 \mathrm{~cm}^{-1}$ with a high intensity which correspond to the stretching vibration of $\mathrm{O}-\mathrm{H}$ bond and the $\mathrm{NH}_{2}$ group. It shows also characteristics peaks at $1266 \mathrm{~cm}^{-1}$ for $\mathrm{C}-\mathrm{N}$ stretching vibration and at $1620 \mathrm{~cm}^{-1}$ corresponding to the bending vibration of N-H. Other peaks appeared at $2982 \mathrm{~cm}^{-1}$ and 1651 $\mathrm{cm}^{-1}$ which correspond to the aryl C-H stretching and $\mathrm{C}=\mathrm{O}$ (carboxylic acid) stretching vibrations respectively. The PLA FTIR spectrum (Figure 2-2) shows a band corresponding to the $\mathrm{OH}$ stretching vibration of the carboxylic acid at $3497 \mathrm{~cm}^{-1}$, several characteristic peaks of the stretching vibrations of the $-\mathrm{CH}$ appear at $2997-2877 \mathrm{~cm}^{-1}$ and of $-\mathrm{CH}$ deformation at $1456 \mathrm{~cm}^{-1}$, 1382 and $1300 \mathrm{~cm}^{-1}$. At the frequencies of 953 and 920 $\mathrm{cm}^{-1}$, we can find the characteristic bands of skeletal vibrations $(\mathrm{C}-\mathrm{C})$. The $\mathrm{C}=\mathrm{O}$ ester vibration appeared

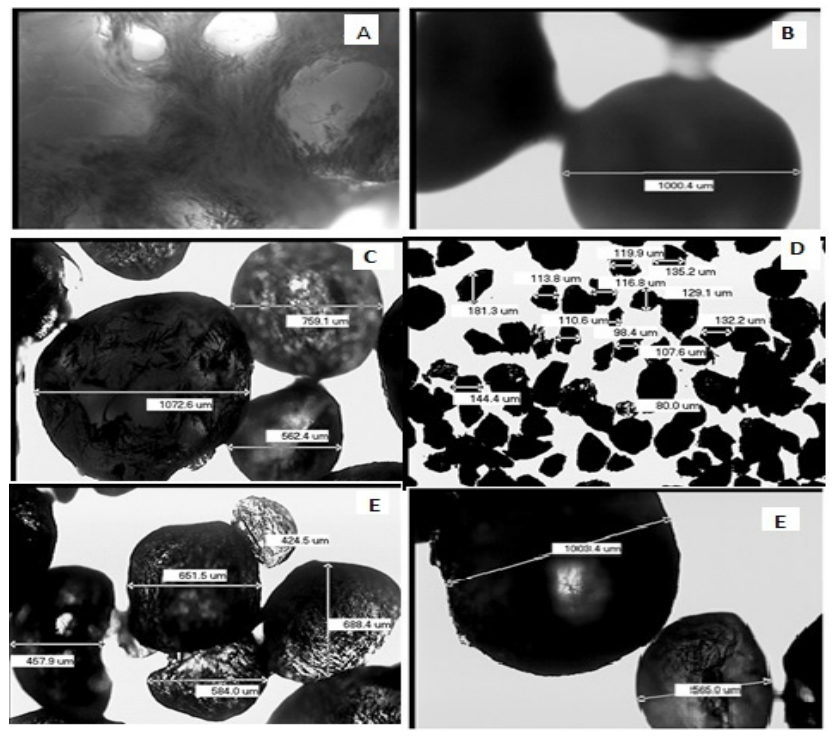

Figure 1: Photomicrographs of the obtained microparticles ( A,B, C. D and E lots )

Table 1: Experimental conditions and organic/aqueous phase's composition

\begin{tabular}{|c|c|c|c|c|}
\hline $\begin{array}{c}\text { Micro } \\
\text { particles lot }\end{array}$ & $\begin{array}{c}\text { \% PVA/ } \\
\text { water } \\
\text { (w:w) }\end{array}$ & $\begin{array}{c}\text { AP:PLA } \\
\text { ratio (w:w) }\end{array}$ & $\begin{array}{c}\text { \%PLA/ } \\
\text { DCM } \\
\text { (w:w) }\end{array}$ & $\begin{array}{c}\text { Stirring } \\
\text { speed } \\
\text { (rpm) }\end{array}$ \\
\hline A & 0.1 & $1: 2$ & 10 & 250 \\
\hline B & 0.5 & $1: 2$ & 10 & 250 \\
\hline C & 0.5 & $1: 1$ & 5.0 & 800 \\
\hline D & 0.5 & $2: 1$ & 2.5 & 800 \\
\hline E & 1.5 & $1: 2$ & 10 & 800 \\
\hline
\end{tabular}

at $1750 \mathrm{~cm}^{-1}$. If we compare the two patterns with microparticles' one, we noted in the spectrum of Sample (D) (Figure 2-3) the presence of the band of the ester group at $1750 \mathrm{~cm}^{-1}$ of PLA and all the bands characteristics of mesalazine.

The differential scanning calorimetry pattern (DSC) of mesalazine (Figure 3-1) shows the presence of an endothermic transition ranging from $280^{\circ} \mathrm{C}$ to $320^{\circ} \mathrm{C}$ where the melting temperature is set at $285^{\circ} \mathrm{C}$. However, in the DSC thermogram of PLA (Figure 3-2), we noted a jump in calorific capacity at $65^{\circ} \mathrm{C}$ which characterizes the glass transition of the material. An endothermic transition ranging from $150^{\circ} \mathrm{C}$ to $170^{\circ} \mathrm{C}$ with a maximum peak at $160^{\circ} \mathrm{C}$ is also observed and the melting temperature is specified at $158^{\circ} \mathrm{C}$. Finally, the thermal behavior of microparticles (Figure 3-3) shows both the melting temperature of mesalazine and PLA. Subsequently, the thermal analysis confirms also the mesalazine encapsulation.

The X-ray diffractogram of mesalazine showed peaks at $7.5^{\circ}, 15^{\circ}, 16.5^{\circ}, 22.5^{\circ}, 24^{\circ}, 27^{\circ}, 28^{\circ}, 30.5^{\circ}, 37^{\circ}, 38^{\circ}$ and $41^{\circ}$. The presence of these peaks indicates that the

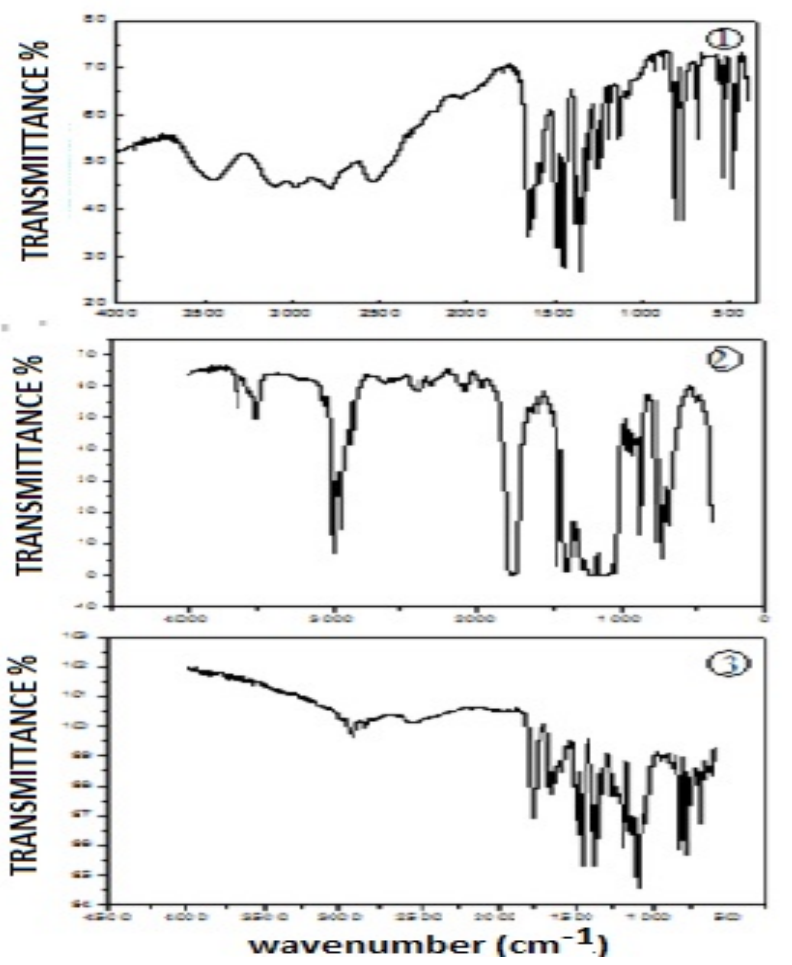

Figure 2: FTIR of : (1) mesalazine, (2) PLA, (3) Lot D of microspheres 
mesalazine is in crystalline form. The X-ray diffractogram of the PLA indicates that the polymer is semicrystalline. In fact, the peaks located at $17.5^{\circ}$ and $20^{\circ}$ indicates the presence of crystalline regions in PLA (Figure 4). However, the X-ray diffraction analysis of microparticles' samples showed also a number of characteristic peaks of mesalazine but with a low intensity. These patterns defined the crystalline structure of the encapsulated mesalazine, the diminution of the peak intensity suggests that there is loses in the drug crystallinity. In fact, Akash et al. ${ }^{25}$ demonstrated that a decrease of the peak intensity of the microencapsulated active ingredient observed in the diffraction patterns (XRD) shows that it is dispersed in the molecular state; but with amorphous parts of structure.

\begin{tabular}{|c|c|c|c|c|c|c|}
\hline \multicolumn{6}{|c|}{ Table 2: Results of microparticles' characteristics } \\
\hline $\begin{array}{c}\text { Micro } \\
\text { particles } \\
\text { lot }\end{array}$ & $\begin{array}{c}\text { Drug } \\
\text { content } \\
\%\end{array}$ & $\begin{array}{c}\text { Entra- } \\
\text {-pment } \\
\text { efficacy }\end{array}$ & $\begin{array}{c}\mathbf{d} 10 \\
(\boldsymbol{\mu m})\end{array}$ & $\begin{array}{c}\mathbf{d} 32 \\
(\boldsymbol{\mu m})\end{array}$ & $\begin{array}{c}\mathbf{d} 43 \\
(\boldsymbol{\mu m})\end{array}$ & $\delta$ \\
\hline A & 12.2 & 36.6 & $*$ & $*$ & $*$ & $*$ \\
\hline B & 16.5 & 49.5 & $*$ & $*$ & $*$ & $*$ \\
\hline C & 16.4 & 32.8 & 708 & 817 & 858 & 1.21 \\
\hline D & 27.5 & 41.3 & 127 & 143 & 150 & 1.19 \\
\hline E & 12.7 & 38.1 & 744 & 838 & 873 & 1.17 \\
\hline
\end{tabular}

*Samples of $A$ and $B$ lots are almost in aggregate form.

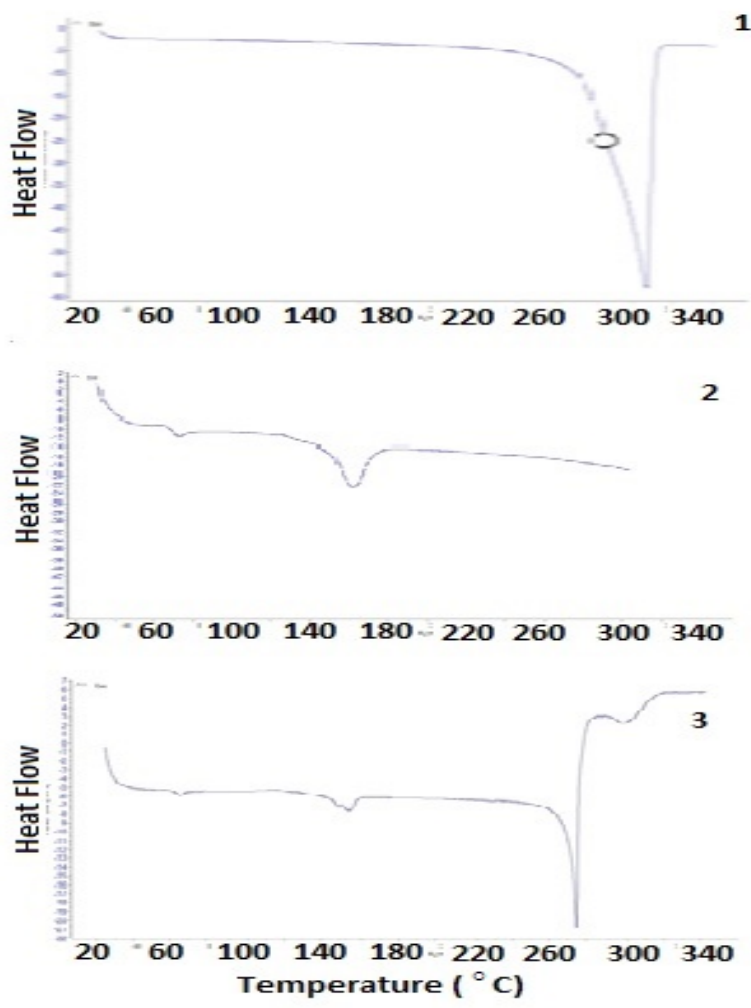

Figure 3: DSC thermographs of: (1) mesalazine, (2) PLA, (3) Lot $\mathrm{D}$ of microspheres

\section{Drug dissolution study}

All formulations were subjected to the in-vitro drug release study both in simulated intestinal fluid SIF $(\mathrm{pH}=6.8)$ and in distilled water for further 6 hours. The percentage of mesalazine released from these formulation as a function of time is given in Figure 5 and 6.

The results showed that the mesalazine was quickly discharged from microparticles of lot D both in distilled water and simulated intestinal fluid. In fact, $100 \%$ and $74 \%$ of drug was released after the first hour in the SIF and distilled water respectively (Table 3 ). The results seem that be coherent since the size of these micropaticles is lesser and consequently, the surface contact of microparticles with the released medium is higher and then the drug release is favoured. However, the

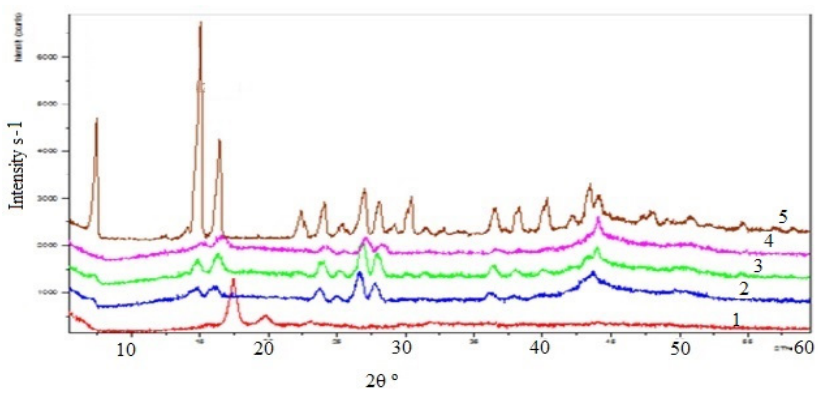

Figure 4: X-Ray diffraction analysis of (1) PLA, (2) microparticules of lot C, (3) lot D, (4) lot E and (5) pure mesalazine

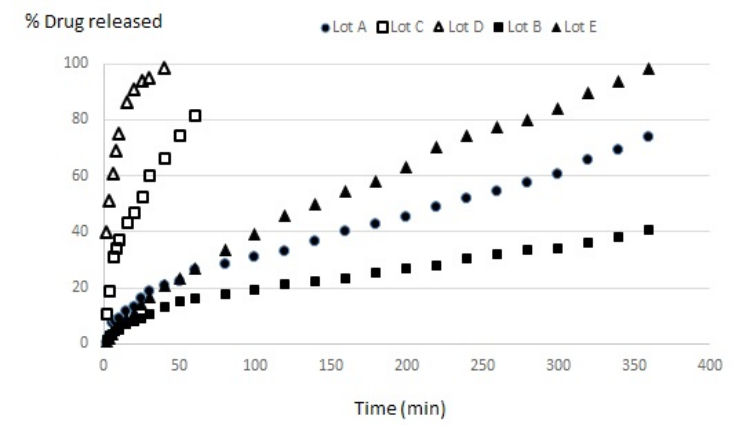

Figure 5: \%drug released from all formulations as a function of time in SIF $(\mathrm{pH}=6.8)$.

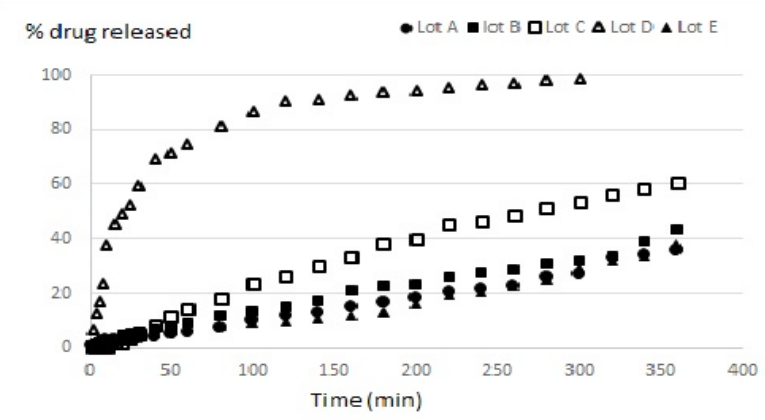

Figure 6: \%drug released from all formulations as a function of time in distilled water 


\begin{tabular}{|c|c|c|c|c|c|c|c|c|c|}
\hline \multirow[t]{2}{*}{$\begin{array}{l}\text { Release } \\
\text { medium }\end{array}$} & \multirow[t]{2}{*}{ Lot } & \multicolumn{3}{|c|}{ Higuchi's equation } & \multicolumn{3}{|c|}{$\begin{array}{c}\text { Korsmeyer-Peppas' } \\
\text { Equation }\end{array}$} & \multirow[t]{2}{*}{$\begin{array}{c}\% \text { drug released after } \\
1 \text { hours }\end{array}$} & \multirow[t]{2}{*}{$\begin{array}{c}\% \text { drug released after } \\
5 \text { hours }\end{array}$} \\
\hline & & $K H^{*} 100$ & $a * 100$ & r2 & $\mathbf{n}$ & KK & r2 & & \\
\hline \multirow{5}{*}{$\begin{array}{l}\text { Distilled } \\
\text { water }\end{array}$} & A & 1.47 & -3.15 & 0.9567 & 0.70 & 0.0043 & 0.9732 & 6.08 & 27.23 \\
\hline & B & 2.01 & -4.44 & 0.9823 & 0.72 & 0.0051 & 0.9972 & 9.00 & 32.23 \\
\hline & $\mathrm{C}$ & 3.73 & -12.21 & 0.9853 & 1.32 & 0.0003 & 0.9704 & 14.43 & 53.37 \\
\hline & D & 13.15 & -11.56 & 0.9668 & 0.79 & 0.0437 & 0.9593 & 74.88 & 98.60 \\
\hline & E & 1.12 & -1.84 & 0.9833 & 0.83 & 0.0022 & 0.9868 & 7.22 & 29.09 \\
\hline \multirow[t]{5}{*}{ SIF } & A & 3.36 & -1.65 & 0.9923 & 0.72 & 0.0125 & 0.8793 & 26.42 & 60.70 \\
\hline & B & 2.03 & -0.88 & 0.9948 & 0.57 & 0.0135 & 0.9900 & 16.36 & 34.00 \\
\hline & C & 10.69 & 0.83 & 0.9697 & 0.56 & 0.0930 & 0.9471 & 81.94 & 100.0 \\
\hline & D & 19.31 & 13.06 & 0.9956 & 0.39 & 0.3011 & 0.9983 & 100.0 & 100.0 \\
\hline & E & 4.88 & -8.98 & 0.9938 & 0.86 & 0.0076 & 0.9801 & 27.07 & 83.76 \\
\hline
\end{tabular}

SIF: simulated intestinal fluid

microparticles of lots B and E exhibited a slow drug release. Also, we remarked that for all formulations, the drug release was faster in the simulated intestinal liquid, the result is certainly related to the high drug solubility in this media ( $\mathrm{pH}$ closed to 7).

The results of data analysis are regrouped in Table 3, The Higuchi and Korsmeyers-Peppas models were verified until $60 \%$ of drug released. The data analysis according to the Higuchi's equation confirmed also the rapid drug release from " $\mathrm{D}$ " formulation where the release constant $\mathrm{KH}$ values were higher (Table 3). In addition, the $\mathrm{KH}$ values in the simulated intestinal fluid were also greater than that in distilled water. Also, the microparticles of lot D showed a burst effect of drug release in the buffer medium. The comparison between the spherical microparticles of lot C, D and E showed that the microparticles of lot $\mathrm{E}$ discharged the mesalazine with a low release constant, the result can be explained by both the high concentration of polymer and microparticles' size.

On the basis of the coefficient of correlation value, the mechanism of the drug release is discussed; in fact a model which gave a highest $\mathrm{r}^{2}$ value is considered as the appropriate model. The most suitable kinetic models for describing the release of mesalazine from the matrix microspheres were Higuchi and/or Korsmeyer-Peppas models since the coefficient of correlation exceeded 0.97; the Hixon-Crowell model assessments gave values of coefficient of correlation lesser than 0.7 for all formulations, then we have not exposed the corresponding results. Thus, the results confirmed that there is no changes in microparticles' surface or diameter during the dissolution process. According to Higuchi or Korsmeyer-Peppas models, the drug dissolution is governed by diffusion for all the studied formulations and in the two media dissolution. By applying the KorsmeyerPeppas model, the diffusion type can be discussed. As a matter of fact, the exponent $\mathrm{n}$ can characterize the drug release mechanisms as a Fick's diffusion when $\mathrm{n}=0.5$ and as a non-Fickian model when $\mathrm{n}>0.5$.

From the data analysis results, exponent $\mathrm{n}$ varied from 0.39 to 1.32 (Table 3); therefore, we concluded that for all formulations except lot D and especially in the SIF, the drug release is governed by diffusion, according to the non-Fickian mechanism since $\mathrm{n}>0.5$, in this case, the diffusion is anomalous and it can include both diffusion and erosion phenomena which can be due to the hydrolysis PLA short chains. For the lot D, the drug dissolution in the buffer solution was more rapid and the $\mathrm{n}$ exponent was lower than 0.5 and in this case the drug dissolution mechanism can be related to the quasiFickian model.

\section{CONCLUSION}

The present investigation was devoted to the elaboration of PLA/Mesalazine microparticles. The optimization of the experimental conditions of the microencapsulation process by varying some parameters permitted to determine the favoured conditions to obtain individualized and spherical or semi-spherical microparticles with a lower emulsifier concentration. In fact, the microparticles of lot $C$ appeared with more spherical shape and mean diameter closed to $700 \mu \mathrm{m}$. Also, small and spherical microparticles were obtained where the emulsifier concentration was increased (lot D). Different release profiles were obtained with different release constant (lots C, D, E). Regarding the individualized microparticles, the prolonging of mesalamine release was achieved when the microspheres were prepared in the experimental conditions "E". The drug release seems that be 
governed by diffusion and in general according to the non-Fickian behaviour.

\section{ACKNOWLEDGEMENT}

The authors are very grateful to the pharmaceutical SALEM Laboratory of El-Eulma-Setif, Algeria.

\section{CONFLICT OF INTEREST}

None

\section{ABBREVIATION USED}

PLA: poly(lactic acid); PVA: polyvinylalcohol.

\section{REFERENCES}

1. French DL, Mauger JW. Evaluation of the physicochemical properties and dissolution characteristics of mesalamine: re1evance to controlled intestinal drug delivery. Pharmaceutical Research. 1993;10(9):1285-90.

2. French DL, Himmelstein KJ, Mauger JW. Physicochemical aspects of controlled release of substituted benzoic and naphthoic acids from Carbopol gels. Journal of Controlled Release. 1995;37(3):281-9.

3. Collier HO, Francis A, McDonald-Gibson WJ, Saeed SA. Inhibition of prostaglandin biosynthesis by sulphasalazine and its metabolites. Prostaglandins. 1976;11(2):219-25.

4. Sharon P, Ligumsky M, Rachmilewitz D, Zor U. Role of prostaglandins in ulcerative colitis. Enhanced production during active disease and inhibition by sulfasalazine. Gastroenterology. 1978;75(4):638-40.

5. Gary R. Lichtenstein, Novel Formulations and Dosing Strategies for 5-ASA. Gastroenterology and Hepatology. 2008;4(12):28.

6. Nidhi MR, Veerpal K, Supandeep SH, Saurabh S, Neeraj M. Microparticles as controlled drug delivery carrier for the treatment of ulcerative colitis: A brief review. Saudi Pharmaceutical Journal. 2016;24(4):458-72

7. Atyabi F, Vahabzadeh R, Dinarvand R. Preparation of Ethylcellulose Coated Gelatin Microspheres as a Multiparticulate Colonic Delivery System for 5-Aminosalicilic Acid. Iranian Journal of Pharmaceutical Research. 2004;2:81-6.

8. Kakar S, Batra D, Singh R. Preparation and evaluation of magnetic microspheres of mesalamine (5-aminosalicylic acid) for colon drug delivery. Journal of Acute Disease. 2013;2(3):226-31

9. Abd El-Bary A, Ahmed AA, Ibrahim MAS. Influence of Some Formulation Variables on the Optimization of $\mathrm{pH}$-dependent, Colon-targeted, Sustained- release Mesalamine Microspheres. AAPS Pharm Sci Tech. 2012;13(1):7584.

10. Lena N, Bianco-Peled $\mathrm{H}$. Designing a biocompatible hydrogel for the delivery of mesalamine. International Journal of Pharmaceutics. 2015;491(1):170-9.

11. Dinesh K, Kavita S, Satish S. Colon Targeting Guar Gum Microspheres of 5-Aminosalicylic Acid: Evaluation of Various Process Variables, Characterization and In-vitro Drug Release. Indian Journal of Pharmaceutical Education and Research. 2016;50(2).

12. Pertuit D, Moulari B, Betz T, Nadaradjane A, Neumann D, Ismaïli L, et al. 5-Amino salicylic acid bound nanoparticles for the therapy of inflammatory bowel disease. J Control Release. 2007;123(3):211-8.

13. Tyler B, Gullotti D, Mangraviti A, Utsuki T, Brem H. Polylactic acid (PLA) controlled delivery carriers for biomedical applications. Adv Drug Deliv Rev. 2016;107:163-75.

14. Mahajan N, Sakarkar D, Manmode A, Pathak V, Ingole R, Dewade D. Biodegradable nanoparticles for targeted delivery in treatment of ulcerative colitis. Adv Sci Lett. 2011;4(2):349-56.

15. Mahajan N, Sakarkar D, Manmode A. therapeutic potential of biodegradable mesalamine microspheres in the treatment of ulcerative colitis. Asian Journal of Pharmaceutical and Clinical Research. 2011;4(1):120-25.

16. Costa P, Souza LJM. Modeling and comparison of dissolution profiles. Eur J Pharm Sci Rev. 2001;13(2):123-33.

17. Higuchi T. Rate of release of medicaments from ointment bases containing drugs in suspension. J Pharm Sci. 1961;50:874-5.

18. Higuchi T. Mechanism of sustained-action medication. Theoretical analysis of rate of release of solid drugs dispersed in solid matrices. J Pharm Sci. 1963;51:802-4.

19. Costa P, Ferreira DC, Souza LJM. Nitroglicerina em sistemas de liberaçào transdérmica-determinaçào da velocidade de libertaçào. Rev Port Farm. 1996;46:4-8.

20. Desai SJ, Singh P, Simonelli AP, Higuchi WI. Investigation of factors influencing release of solid drug dispersed in inert matrices. III. Quantitative studies involving the polyethylene plastic matrix. J Pharm Sci. 1966a;55:1230-4.

21. Desai SJ, Singh P, Simonelli AP, Higuchi WI. Investigation of factors influencing release of solid drug dispersed in inert matrices. IV. Some studies involving the polyvinyl chloride matrix. J Pharm Sci. 1966b;55:1235-9.

22. Korsmeyer RW and Peppas NA, J Control Rel 1983; 1:89-98.

23. Hixon AW, Crowell JH. Ind Eng Chem 1931; 23:923-31,

24. Elbahri Z, Taverdet J-L. Elaboration and characterisation of microparticles loaded by pesticide model. Powder Technology. 2007;172:30-40

25. Akash M, Iqbal F, Raza M. Characterization of EC and HPMC microspheres for controlled realese of Flurbiprofen. Journal of Pharmaceutics and Drug Delivery Research. 2013;2:1.

\section{PICTORIAL ABSTRACT}

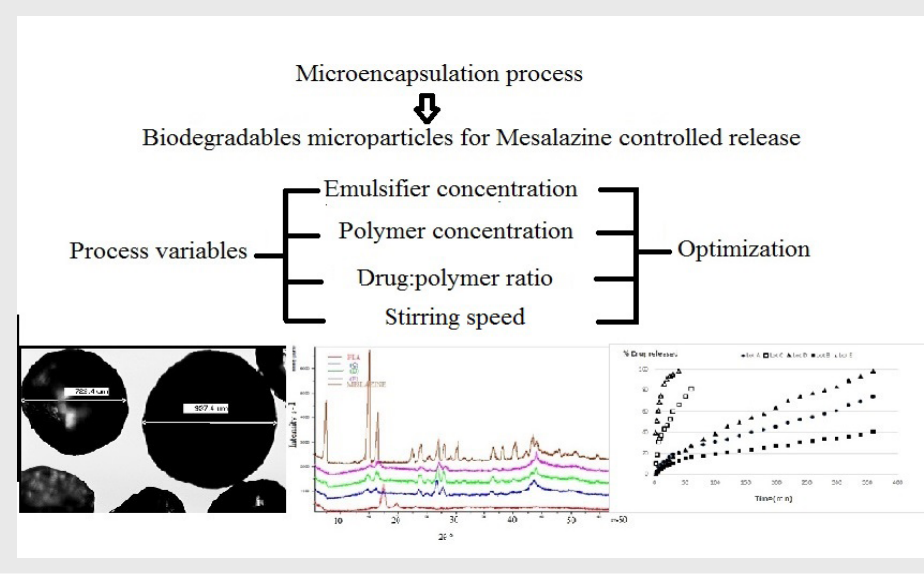




\section{SUMMARY}

- Microparticles based on biodegradable polymer i.e. polylactic acid and loaded by an anti-inflammatory agent which is Mesalazine (5-aminosalicylic acid) were obtained using microencapsulation by emulsion - solvent evaporation process.

- Some of the process variables i.e. the emulsifier concentration, the polymer concentration, the drug: polymer ratio and stirring speed were varied for the microparticles' optimization.

- The results demonstrated that the microparticles' morphology depended strongly on the emulsifier concentration and the drug entrapment depended both on the initial drug:polymer ratio and polymer concentration.

- - The mesalazine release is fully slow downed using the microparticles with $\mathrm{d} 10=744 \mu \mathrm{m}$ and for all formulations, the release mechanism seemed that be governed by diffusion.

\section{About Authors}

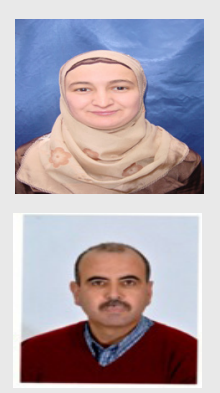

Wafa Benabid: Master degree in pharmaceutical process engineering, Department of process engineering, Setif, Algeria.

Ferhat Djerboua: PhD, lecturer at University Ferhat Abbas, Department of process engineering, Setif, Algeria.

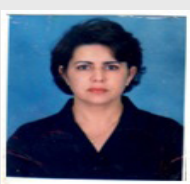

Milad Baitiche: Professor at University Ferhat Abbas, Department of process engineering, Setif, Algeria.

Amor Maiza: Pharmacist and technical director in SALEM Laboratory of El-Eulma-Setif, Algeria.

Zineb El bahri: Professor at University Djillali Liabes, Department of chemistry, Sidi Bel Abbes, Algeria

Cite this article: Banabid W, Djerboua F, Maiza A, Bahri ZE, Baitiche M. Optimization and in-vitro Evaluation of Poly (lactic acid) /Mesalazine Microspheres as Drug Carriers. Indian J of Pharmaceutical Education and Research. 2017;51(2S):S46-S53. 